SARA SEAGER

\section{EXTRASOLAR GIANT PLANETS UNDER STRONG STELLAR IRRADIATION (1999)}

A flicker of embarrassment crosses Sara Seager's face when she is asked whether there are any mistakes in her thesis. "I definitely have at least one typo. I know where it is, unfortunately. I hate to talk about it." She thinks for a moment, her thesis unopened on the desk before her. "Now that you mention it, I should probably go back and correct it with a pen."

There is little else for Seager to regret about her thesis. She is now a planetary scientist at the Massachusetts Institute of Technology in Cambridge, and, unusually, her $\mathrm{PhD}$ helped to found a field. "It might have been one of the first - if not the first - PhD theses on exoplanets," she says.

In 1996, when Seager started her postgraduate studies at Harvard University in Cambridge, just half a dozen planets had been spotted orbiting distant suns. They could be detected only indirectly, mostly by capturing the 'wobble' that an orbiting planet caused in the movement of a star. And the signals were noisy - some astronomers didn't believe that exoplanets were real.

Seager was encouraged to enter the field by her supervisor at Harvard,
Dimitar Sasselov, who was keen to take a different approach. Sasselov encouraged Seager to study the atmospheres of exoplanets to find ones that might harbour interesting chemistry or indicate life. This seemed unlikely to work when the planets themselves were so difficult to detect. "It was a big risk at the time: a non-tenured professor and a grad student. Despite the advice otherwise of colleagues in the department, we went ahead," Sasselov says.

Seager built a theoretical model suggesting that it should be possible to see starlight bouncing off a planet that was orbiting its star closely, and that analysing that light would reveal a fingerprint of the planet's chemical constituents, temperature and pressure ${ }^{1}$. Shortly afterwards, during her postdoc, she predicted that it should be possible to spot clouds in the atmosphere, and that one of the easiest elements to detect would be sodium² ${ }^{2}$.

It was tough going. She derived equations to represent the components of a planet's atmosphere and then, after teaching herself to code, plugged them into the computer models she was building. Her hours were long and isolated, and she would often hit programming bugs that threatened to derail her work. Meanwhile, ex-students from her department were calling from Silicon Valley: their companies were seeking people like her. "I was far from committed to a career in science. I often thought of leaving," she says.

Yet Seager "always expressed a certainty about what she was working on", recalls David Charbonneau, a contemporary of hers at Harvard who now leads an astronomy group there, and was using Seager's theoretical predictions to explain his observational results. He describes her as a

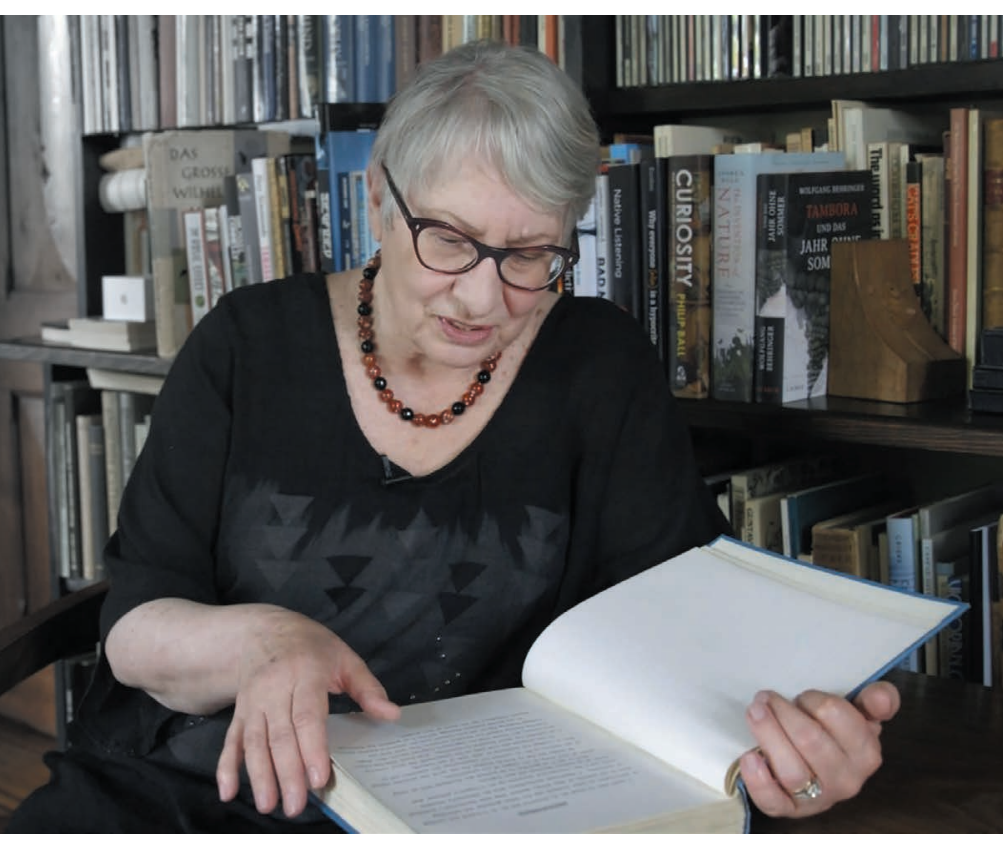

UTA FRITH

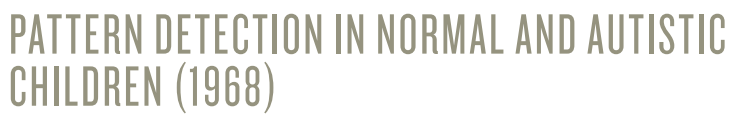

ff have not looked at this in decades," declares Uta Frith as she retrieves her thesis from a study in her Victorian house in suburban London. The book, bound in sky-blue cloth, nestles on a low shelf, right next to a science-fiction encyclopaedia. She dusts it off with a cloth and opens it to the typewritten title page. "It looks very charming and childish. That's really my immediate impression. I did want a short and an interesting title."

The title is as brief as Frith's PhD was: she had only two years of funding, starting in September 1966, and at the end of 1968 she duly turned in the thesis: 205 pages, typed up by a secretary from her handwritten manuscript. The bibliography is concise, just 10 generously spaced pages. "So little was known about autism at the time that this was the extent of the references I found," she says. Today, the developmental disorder is the subject of several thousand publications each year.

Frith came to London from her native Germany in 1964 to attend a course in abnormal psychology at the Institute of Psychiatry. There, for the first time, she met children with autism, and was "completely fascinated. I still am," she says. She also met her future supervisors, psychologists Beate Hermelin and Neil O'Connor. At that time, autism spectrum disorders were poorly understood and carried a stigma. Those diagnosed were usually only the severe cases, children with profound intellectual and linguistic difficulties. The mainstream view in psychiatry was that autism was a product of a child's upbringing and environment and that distant, unloving parents - particularly mothers - were to blame.

Frith refused to subscribe to that view. "I was always struck, when I met the parents of these children, how little they corresponded to what was told about them in the literature," she says. The question that interested Frith was whether the children might process information differently from other kids. To investigate this, she showed children a simple box containing green and yellow counters that were arranged in a specific pattern. She then covered up the box and asked the child to build the sequence from memory.

She often travelled to hospitals to test children with autism, as well as to nurseries and schools to assess children in her control group. She plugged the data into mechanical calculators that were "very, very noisy" and then took the better part of a day to perform the statistical analysis.

Frith turns to the later pages of her thesis to remind herself of what she found, well aware of how dated - even naive - it might sound. "I'm a little bit afraid of this now. What nonsense can it be?" She 
